Portland State University

PDXScholar

10-29-1991

\title{
Effects of Encouraging, Discouraging, and Neutral Instructions on Naming by Aphasic Subjects
}

Denise Marie Nelson

Portland State University

Follow this and additional works at: https://pdxscholar.library.pdx.edu/open_access_etds

Part of the Speech and Hearing Science Commons

Let us know how access to this document benefits you.

\section{Recommended Citation}

Nelson, Denise Marie, "Effects of Encouraging, Discouraging, and Neutral Instructions on Naming by Aphasic Subjects" (1991). Dissertations and Theses. Paper 4194.

https://doi.org/10.15760/etd.6077

This Thesis is brought to you for free and open access. It has been accepted for inclusion in Dissertations and Theses by an authorized administrator of PDXScholar. Please contact us if we can make this document more accessible: pdxscholar@pdx.edu. 
AN ABSTRACT OF THE THESIS OF Denise Marie Nelson for the Master of Science in Speech Communication: Speech and Hearing Science presented October 29, 1991.

Title: Effects of Encouraging, Discouraging, and Neutral Instructions on Naming by Aphasic Subjects.

APPROVED BY THE MEMBERS OF THE THESIS ${ }_{\lambda}$ COMMITTEE: $^{-}$

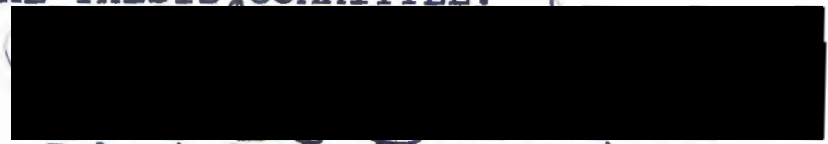

Robert Casteel, Co-Chair
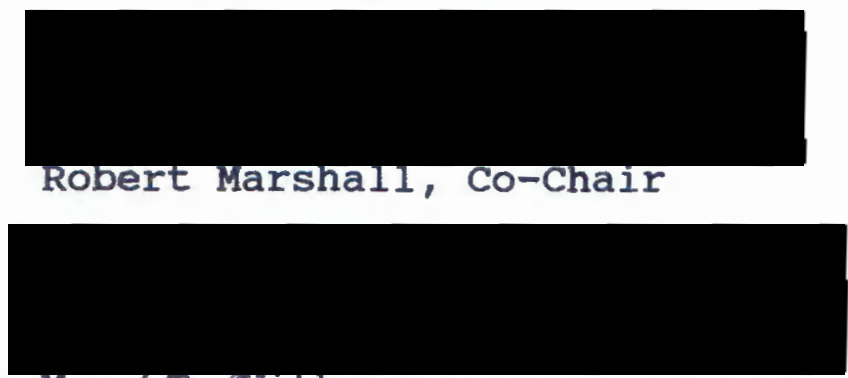

Mary T.JWIthers

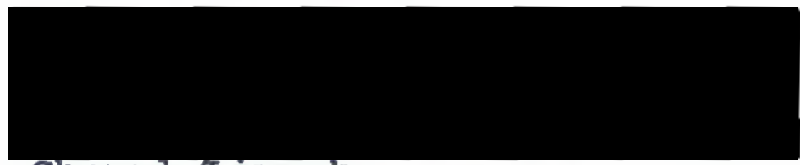

Chery 1 Livneh

The purpose of this investigation was to examine the influence of three instructional conditions (encouraging, discouraging, and neutral) on eighteen aphasic adults' performance on a naming task. Each subject listened to each audiotaped instructional condition followed by a 20 picture naming task presented with a slide projector for a total of three tasks and 60 pictures. Subjects' mean scores were 
combined and averaged to derive a grand mean score for each Instructional condition. A repeated measures analysis of variance was applied to determine if the differences were significant at the .01 level. No significant differences were found. 
EFFECTS OF ENCOURAGING, DISCOURAGING, AND NEUTRAL INSTRUCTIONS ON NAMING BY APHASIC SUBJECTS

by

DENISE MARIE NELSON

A thesis submitted in partial fulfillment of the requirements for the degree of

MASTER OF SCIENCE

in

SPEECH COMMUNICATION :

SPEECH AND HEARING SCIENCE

Portland State University

1991 
TO THE OFFICE OF GRADUATE STUDIES:

The members of the Committee approve the thesis of Denise Marie Nelson presented October 29, 1991.

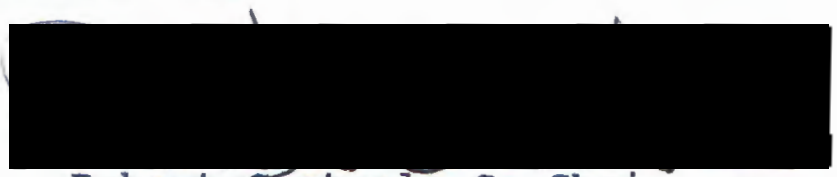

Robert rasteel, Co-Chair

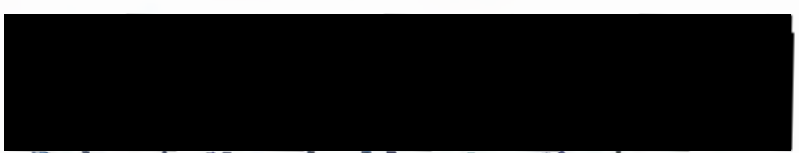

Robert Marshall, co-Chair

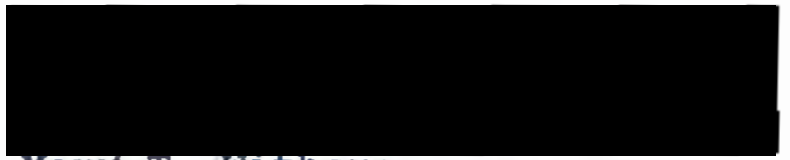

Mary $\%$ withers

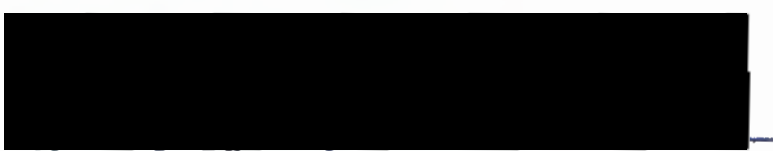

Chery 1 Livneh

APPROVER.

Theodore G. Grove, Chair, Department of Speech Communication

c. William Savery, Interim Vice Provogt for Graduate studies and Research 


\section{ACKNOWLEDGEMENTS}

I would like to extend my sincerest appreciation to various individuals for their help and encouragement during this project.

I am deeply indebted to Dr. Robert Marshall for his guidance and patience. I would like to extend my deepest gratitude to Dr. Robert Casteel for his enthusiastic support and continuous reassurance. I wish to thank Mary T. Withers and Cheryl Livneh for their helpful suggestions in preparing the final draft and participation during my oral defense. A special thanks to Dr. David Phillips for his expert advice and assistance in the research design and statistical analysis.

I extend my sincerest thanks to Kimberley Ellis, not only for her help with reliability data, but for always being there when I needed reassurance. A special thanks to the gentlemen and women who participated in this study. I would like to express my gratitude to my parents who have given me their unconditional love and financial support through the past years. Lastly, I wish to thank Jim Benville for his loving support and encouragement throughout this project. This project would not have been possible without the help of these people. 
TABLE OF CONTENTS

PAGE

ACKNOWLEDGEMENTS ........................ ii

LIST OF TABLES....................... vi

IIST OF FIGURES....................... vii

CHAPTER

I INTRODUCTION AND STATEMENT OF PURPOSE....... 1

Introduction.................... 1

Statement of Purpose.............. 3

II REVIEW OF THE LITERATURE.............. 4

Physical Factors................ 5

Anxiety

Fatigue

Distractors

Medications

Psychosocial Factors.............. 9

Motivation

Pre-morbid Personality

Attitudes of Communicative Partners

III METHODS AND PROCEDURES.............. 18

Methods..................... 18

Subjects

Experimental Task

Experimental Conditions

Procedures.....................

Experimental Task

Scoring 
Scoring Reliability for Naming Task Responses

IV RESULTS AND DISCUSSION.............. 27

Results................... 27

Data Analysis

Discussion................... 29

Group Design

Experimental Conditions

Content of Instructions

Feedback

other Methodological Differences

v SUMMARY AND IMPLICATIONS ............ 36

Summary................... 36

Implications................. 37

Clinical Implications

Further Research Implications

REFERENCES..........................

APPENDICES

A DESCRIPTION OF APHASIC SUBJECTS.......... 45

B StIMULUS LISTS.................. 46

C ORDER OF PRESENTATION OF INSTRUCTIONS....... 47

D MEAN SCORES FOR APHASIC SUBJECTS UNDER EACH INSTRUCTIONAL CONDITION. ........... 48

E SUBJECTS' RESPONSES TO EXPERIMENTER'S

QUESTION..................... 


\section{LIST OF TABLES}

TABLE

PAGE

I Scoring system.................... 25 


\section{LIST OF FIGURES}

FIGURE

PAGE

1. Experimental Set Up................. 23

2. Group Means for Instructions............ 28

3. Group Means for Naming Task............ 29 
CHAPTER I

INTRODUCTION AND STATEMENT OF PURPOSE

\section{INTRODUCTION}

Several studies suggest that physical and psychosocial factors may affect the language performance of individuals with aphasia. Among these factors shown to be detrimental are those such as anxiety, fatigue, time pressure, and distractors (Basili, Diggs, \& Rao, 1980; Brookshire, 1971; Brookshire, Nicholas, Redmond, \& Krueger, 1979; DeRenzi, Faglieni, \& Previdi, 1978; Eisenson, 1984; Marshall \& King, 1973; Marshall, Tompkins, \& Phillips, 1980; Stoicheff, 1960). Other factors such as relaxation training and desensitization procedures can positively influence an aphasic individual's ability to communicate (Marshall \& Watts, 1976; Vogel, 1986). In addition to these factors, the aphasic individual's motivation to communicate is also felt to be important (Brookshire, 1986; Dreher, Ege, \& Harrold, 1980; Eisenson, $1984)$.

The attitudes and behaviors of the aphasic individual's communicative partners may also affect language performance. Various studies have investigated the influence of supportive and non-supportive partners, nonverbal communication, degrading comments, and instructions which relay the partner's 
expectations of communicative ability (Biorn-Hansen, 1957; Brumfitt \& Clarke, 1983; Chester \& Egolf, 1974; Dubner, 1972; Eisenson, 1963; Skelley, 1975; Stoicheff, 1960). The present study is concerned with the effects of instructions on an aphasic individual's ability to communicate.

In 1960, Stoicheff examined the effects of encouraging, discouraging, and neutral instructions on aphasic subjects' naming and oral reading performance. She found that the type of instructions given to the subjects in conjunction with feedback commensurate with type of instructions significantly affected their performance on the language tasks. The group who received encouraging instructions performed significantly better than the groups who received discouraging and neutral instructions. stoicheff pointed out that instructions (encouraging) referring to the ease of the task and to the expectation that the aphasic will perform well may reduce anxiety and enhance performance. Conversely, discouraging instructions implying that the task is difficult and that the patient will perform poorly will hinder performance.

Treatment and assessment tasks require instructions. The findings of the stoicheff (1960) study suggest that clinical aphasiologists be careful about how instructions are given. Specifically, the findings tell us to use encouraging or neutral but not discouraging instructions to obtain the patient's optimal performance. This practice poses a problem 
because there are occasions when the clinician must ask the patient to attempt a task that will be difficult, primarily because how well or how poorly the patient performs on the task may be relevant to making decisions about rehabilitation, independent living, judgement, work, or some other factor. Although the findings of the stoicheff study appear to be straight forward, a careful reading of the methods employed indicates that the subjects were presented positive, negative, and no feedback in combination with encouraging, discouraging, and neutral instructions. Thus, the implications derived may be somewhat misleading in that the effects of instructions may not have been isolated.

\section{STATEMENT OF PURPOSE}

The purpose of this study was to determine the effects of instructions on aphasic adults' performance on a naming task. The null hypothesis for the present study is that aphasic subjects' performance on a naming task will not be significantly affected by encouraging, discouraging, or neutral instructional conditions. The study was designed to confirm or reject this null hypothesis. 
CHAPTER II

REVIEW OF THE LITERATURE

Aphasia is a language processing deficit caused by brain injury (Brookshire, 1986). More specifically, any of the following language abilities may be affected by brain injury: understanding the speech of others, speaking, reading, writing, using gestures, understanding the gestures of others, and arithmetic (Broida, 1979). Besides the effects of the brain injury, various physical and psychosocial factors can affect the language performance of individuals with aphasia. These factors may also "account for the differential rates and degrees of improvement among adult aphasic patients" (Eisenson, 1963, p. 506). Under optimal conditions, aphasic patients can perform at their greatest potential; for this reason, it is critical to know which factors affect their ability to communicate (Eisenson, 1984).

The purpose of this chapter is to discuss some of the physical and psychosocial factors that affect the language performance of aphasic individuals. 
PHYSICAL FACTORS

\section{Anxiety}

The term anxiety signifies fear or apprehension about a situation or undertaking (Dorland's Medical Dictionary,

1965). Aphasic persons, like their normal counter parts, can become anxious because of poor performance, time pressure, or any other situation they perceive as threatening. Brookshire (1972) presented a naming task to aphasic subjects using words they could name easily and words they had marked difficulty naming. When difficult-to-name items were inserted into lists of easy-to-name items, the subjects tended to make errors on items that they had previously named easily. Another study by Brookshire (1976) examined the effects of task difficulty on the sentence comprehension performance of aphasic subjects. Again, the interspersing of a small number of difficult commands in a larger set of easy commands interfered with the subjects' performance to commands that ordinarily would have been easy. Implications of these studies are that errors may cause the subject to become anxious and, thus, prompt more errors.

Aphasic patients often ask their listener for more time to respond (Skelley, 1975; Wender, 1990). Brookshire (1971) has illustrated that aphasic subjects perform significantly better on a naming task when given more time to name and when allowed to self-pace their naming trials. He found that 
correct naming was significantly higher for a group of aphasic subjects when stimuli were exposed for five or more seconds than when they were exposed for three seconds. In the same study, he found that subjects had higher naming scores on self-paced trials than machine paced trials of a comparable duration.

It has been shown that relaxation and desensitization procedures may potentially reduce aphasic patients' anxiety and improve their ability to communicate (Eisenson, 1984). Marshall and Watts (1976) compared aphasic subjects' performances on four verbal subtests (sentence production, naming, sentence completion, and repetition) scored with the multidimensional scoring system of the Porch Index of Communicative Ability (PICA) (Porch, 1967). They found that subjects had significantly higher overall verbal and naming scores after a period of relaxation training than after sitting alone in a room for a comparable period of time. Vogel (1986) used a hierarchy of speaking situations to systematically desensitize an aphasic patient to increasingly difficult speaking situations. The patient improved in his communication performance as demonstrated by periodic reevaluations with the PICA.

\section{Fatigue}

When an aphasic individual is fatigued, his ability to communicate may be detrimentally affected (Eisenson, 1984; 
Marshall \& King, 1973; Marshal1, Tompkins, \& Phillips, 1980; Tompkins, Marshall, \& Phillips, 1980). Marshall and King conducted a study to determine whether scores on the PICA would be significantly affected following periods of isokinetic exercise or periods of rest. The results showed that the subjects' PICA scores were significantly lower following exercise than rest, specifically on the verbal and graphic tasks. Marshall and King concluded that an aphasic patient's communication can be negatively affected by fatigue, such as fatigue that might occur in physical therapy.

Aphasic patients sometimes report that they communicate better in the morning than in the late afternoon when fatigue sets in (Buck, 1968). Marshall, Tompkins, and Phillips (1980) examined the effects of scheduling on the assessment of eight chronic and eight acute aphasic adults with the PICA. In a second study, Tompkins, Marshall, and Phillips (1980) assessed the effects of morning and afternoon scheduling with 16 aphasic adults participating in a rehabilitation program. Both investigations found that subjects performed significantly higher on the PICA when tested in the morning than in the afternoon. These results suggest that the time the patient is scheduled for evaluation is an important consideration and that periodic testing times (morning versus afternoon) are consistent from evaluation to evaluation to prevent affecting test results as a consequence of scheduling. 


\section{Distractors}

In addition to fatigue and anxiety, various types of distractors can reduce an aphasic patient's communicative efficiency (Eisenson, 1984). Distractors, such as noise, can divert attention or interrupt concentration of an aphasic patient. DeRenzi, Faglioni, and Previdi (1978) conducted a study to examine the effects of a distractor task during three conditions: no delay, 20 second unfilled delay, and 20 second filled delay (subject was required to count backwards). The results revealed that a filled delay adversely affected the comprehension ability of aphasic subjects. Basili, Diggs, and Rao (1980) investigated the effects of quiet, white noise, and speech on The Token Test (McNeil \& Prescott, 1978) performance of aphasic subjects. They found that the subjects' performance decreased in the presence of speech. The overall results of these studies suggest that distractors such as speech and filled delay tasks are deterrents to optimal performance of aphasic patients.

\section{Medications}

Past research has shown that various medications, such as sodium amytal (a sedative, hypnotic, and anti-convulsant), meprobamate (a tranquilizer, muscle relaxant, and anticonvulsant), and hyerbaric oxygen do not facilitate language performance of aphasic individuals (Bergman \& Green, 1951; Billow, 1949; Linn, 1947; Sarno, Sarno, \& Diller, 1972; West 
\& Stockel, 1965). Darley, Keith, and Sasanuma (1977) studied the effects of ritalin (an alerting drug) and librium (a tranquilizing drug) on aphasic individual's language performance. The researchers hypothesized that these drugs would improve alertness and attentiveness and reduce anxiety and tension. However, their results were insignificant. Altschuler (1974) investigated the effects of supplemental oxygen respiration on hemiplegic aphasic adults. She found a slight but significant improvement on PICA overall scores when supplemental oxygen was administered.

Speech-Language Pathologists working with aphasic patients should be aware of the factors discussed above and how they affect, both positively and negatively, aphasic patients' ability to communicate.

\section{PSYCHOSOCIAL FACTORS}

When an aphasic adult begins to recover from the brain injury, he may be devastated by his acquired language problems. While organic problems will limited his ability to recover fully, the patient's motivation and pre-morbid personality may interact with the factors previously reviewed and affect his communicative ability (Brookshire, 1986; Eisenson, 1963, 1984). 
Motivation

The importance of motivation to aphasia therapy and its outcome has been raised by many writers but objective studies of motivation and its role in treatment are lacking (Eisenson, 1963; Shill, 1979; Wepman, 1953). Eisenson cited the importance of motivation in the following statement: "the will to do well and belief that he can and is doing well underlie both the immediate and the ultimate improvement of the aphasic patient" (p. 503). Brookshire (1986) also reported that the severely impaired patient may benefit from treatment if he is highly motivated; however, a patient who is mildly impaired and is not motivated may not benefit from treatment.

Dreher, Ege, and Harrold (1980) have pointed out that the patient's desire to help himself is crucial. They developed a motivational checklist that can be completed by the patient, clinician, or a significant other. The checklist covers five areas: general communication motivation, insight, extroversion, level of aspiration, and rewards. This checklist can be beneficial in the treatment of a patient because it illustrates how the patient views himself and his willingness to work for certain rewards.

\section{Pre-morbid Personality}

Eisenson (1963) discussed the effects of the patient's pre-morbid personality on the effects of brain damage. He 
pointed out that patients who tend to do well are often premorbidly outgoing and optimistic. They have little difficulty "adjusting themselves to group and environmental demands and improve spontaneously with or without direct treatment" (Eisenson, 1963, p. 504). Patients who may not do well are generally pessimistic premorbidly and have problems adjusting to external pressure.

Pre-morbid personality may also influence how the aphasic patient copes with the residuals of a stroke. Florence and Conway (1986) mentioned that the patient suddenly moves from a state of being in total control of his or her activities to a near-dependent state. To manage these unexpected changes, aphasic patients must draw upon the coping skills they have developed over a lifetime. They appropriately noted that some individuals are well equipped to do this whereas others are not. These differences in coping skills may, according to Florence and Conway, affect treatment outcomes.

\section{Attitudes of Communicative Partners}

The aphasic person's communication and sense of wellbeing can be affected by the attitudes of his communicative partners. These partners could be friends, family members, caregivers (e.g. physicians, therapists, nurses), and speechLanguage Pathologists. Generally, attitudes that reflect support, encouragement, and represent attempts to motivate the patient are expected to improve communication whereas those 
that reflect indifference, impatience, and insensitivity will hamper communication (Buck, 1968; Eisenson, 1963; Scheull, Jenkins, \& Iminez-Pabon, 1964).

Some objective evidence exists to support the impact of the communicative partner's attitude on aphasics' communication. Malone (1969) and Porter and Dabul (1977) reported that listeners react inappropriately, negatively, and sometimes indifferently to people with aphasia. Duffy, Boyle, and Plattner (1980) found that naive listeners judged the speech of non-fluent aphasic speakers to be significantly worse than that of normal subjects in terms of its composition, clarity, and competency but that these judgements were not applied to fluent aphasic speakers.

Negative attitudes may be conveyed to the aphasic patient without the individual being aware of it. Chester and Egolf (1974) suggested that persons who communicate with aphasic patients may not be aware of their nonverbal behaviors that unwittingly transmit negative attitudes to aphasic persons. They mentioned that negative attitudes can be conveyed in voice, facial expression, body movements, and lack of eye contact. Skelly (1975) provided some limited objective evidence to support this point of view. She interviewed a group of aphasic patients about the care they had received following their stroke. The group reported that behaviors manifested by communication partners such as audible sighs and 
drumming of the fingers affected their morale and motivation adversely. A suggestion for counteracting conveying an attitude of negativism was offered by Dubner (1972) who noted the importance of the clinician using a soft, gentle voice to convey an attitude of encouragement and reassurance to the patient.

Caregivers, physicians, nurses, and other therapists who are not directly responsible for the management of the aphasic patient's communication deficits have been noted to reflect attitudes that are less than optimal when communicating with aphasic patients. Biorn-Hansen (1957) and others (Buck, 1968; Wender, 1989) note that some individuals have a tendency to belittle the patient by talking about him in his presence as if he cannot hear. Lubinski (1986) has suggested that when the aphasic patient is institutionalized in a nursing home, the staff tend to regard the patient as being unable to communicate and seldom provide opportunities for communicative interaction. Corcoran and McAleer (1980) examined the behaviors of counseling students while interacting with aphasic and non-aphasic adults. They reported that the counselors interacted more positively, verbally and nonverbally, with the aphasic adults than the non-aphasic adults. However, the counselors reported less favorable evaluations for the aphasic group in terms of lower intelligence and poorer problem solving skills, suggesting 
that they may hold negative attitudes about aphasic persons even though their interactive behaviors were appropriate. on a more positive note, Ricco-Schwartz (1982) has developed an in-service curriculum for nonmedical professionals, paraprofessionals, and families aimed at creating a positive rehabilitative background for aphasic clients.

Speech-Language Pathologists. The aphasia clinician may see the aphasic patient shortly following the stroke. Therefore, the clinician's attitude is important to the initiation of the rehabilitative process. Wepman (1953) has suggested that the aphasia clinician's treatment at this time be limited to supportive counseling. Biorn-Hansen (1957) found that patients who receive such supportive counseling shortly after their stroke demonstrate fewer problems with role changes, marital discord, and may ultimately be less overprotected by family members. The distinction among early family and patient counseling/education and treatment designed to ameliorate aphasic deficits has been pointed out by several writers (Brookshire, 1986; Marshall, 1987; Wepman, 1953).

When the aphasic patient is ready for formal assessment and subsequent therapy, the attitudes and behaviors of the Speech-Language Pathologist become extremely important. Brookshire, Nicholas, Redmond, and Krueger (1979) explained that there is a two way interactive process between clinician and patient during therapy. The behavior of one affects the 
behavior of the other. They speculated that certain kinds of clinician behaviors and requests might set the stage for errors but found no objective evidence to support this theory. Within the context of aphasia treatment, it has been suggested that the patient will profit most from informational rather than incentive feedback (Brookshire, 1986; Marshall, 1987). The former refers to data provided to the patient about the quality of his response and how closely it approximates the intended target (e.g. "You really worked hard on that one" or "I like the way you corrected yourself"). Incentive feedback refers to motivational responses that reward desired responses and punish non-desirable responses.

Generally, aphasia clinicians seek to reflect an attitude in assessment and treatment settings that will be helpful and encouraging to the patient. There are several reports in the aphasia literature that underscore the importance of this practice. Persons that have recovered from aphasia sufficiently well to write about their therapy have indicated that negative statements from their clinicians as to how well they do in treatment adversely affected their motivation (Buck, 1968; Irwin, 1981; Wender, 1990). Skelly's (1975) interviewees mentioned that they perceived testers' manners as bellicose and indifferent and, that in the testing situation, questions were presented quickly and in a frightening voice. The interviewees stated that this negatively affected their 
motivation and cooperation in the testing situation and increased their anxiety.

Clinician Instructions. Clinicians typically seek to motivate the aphasic client to do his or her best in treatment and assessment situations. It is vital to distinguish among the influence of caregiver attitudes, that have been thoroughly discussed previously, and the task instructions that clinicians provide to patients. In assessing the aphasic patient's strengths and weaknesses, instructions need to be standardized to provide reliable results from test-to-test. Instructions should provide the patient information about what is expected and why he is being asked to perform the particular task (Skelly, 1975).

For decades, aphasia clinicians have operated on the assumption that the nature of the instructions presented to the aphasic patient make a significant difference on how well or how poorly the patient will perform. This point of view largely stems from the results of a study conducted by Stoicheff (1960). She investigated the effects of encouraging, discouraging, and neutral instructions on groups of aphasic subjects' responses on naming and oral reading tasks. The results showed that the group who received discouraging instructions performed significantly poorer on the language tasks than the group who received encouraging and the group who received neutral instructions. On the basis of 
this study, aphasia clinicians have been cautioned as to the content of the instructions they provide to the patient.

A careful reading of the Stoicheff (1960) paper reveals that factors other than the type of instructions could have affected the outcome of the study. Each group was trained over two sessions to perceive the experimenter as encouraging, discouraging, or neutral. This was accomplished by providing feedback to the subject about his potential ability to do the task, his performance, and expectations for performance on the naming and reading tasks. The performance of the groups was compared on the basis of responses obtained during the third testing session. Obviously, this occurred after the subjects had been conditioned to perceive the experimenter as encouraging, discouraging, or neutral. The important issue is that the influence of instructions was not isolated; therefore, the interpretation of stoicheff's results may have been contaminated by the attitudes conveyed by the experimenter to the subjects.

Because instructions during assessment and treatment are so important to the management of aphasic persons, this study was designed to clarify information about the effects of instructions on aphasia language performance in a testing situation that would not be biased by clinician behaviors conveying an attitude of support or lack of it. 
CHAPTER III

METHODS AND PROCEDURES

METHODS

\section{Subjects}

Eighteen aphasic adults from the Veterans Affairs Medical Center (VAMC), Portland, Oregon, participated in the study. The subjects ranged in age from 30 to 68 years old with a mean age of 55.89 years. Sixteen of the subjects were male and two were female. Aphasia resulted from a cerebrovascular accident for 15 subjects, trauma for two subjects, and a tumor for one subject. Time elapsing between onset of aphasia and participation in the study ranged from four to 238 months with a mean value of 64 months. All subjects had an eighth grade education or better. Fifteen of the subjects were premorbidly right-handed and three were left-handed. Severity of aphasia was determined by subjects' most recent overall percentile scores on the Porch Index of Communicative Ability (PICA). These ranged from the 44 th to the 88 th percentile, with a mean percentile score of 74 . All subjects were currently receiving or had received speech and language services at the VAMC. Subjects are described in detail in Appendix A.

Each subject passed a vision screening test which involved the following: four, black and white pictures of 
common objects were presented, one at a time, using a slide projector (Kodak Ektagraphic III; ATS Projector, serial \# A310167). After the presentation of each of the four pictures, the subject selected a matching identical picture from an array of four choices presented on a card. This screening insured that the subjects would be able to see the stimuli on the screen during the experiment. subjects had to match all pictures correctly to be included in the study.

Each subject was administered a hearing screening test using a Beltone Audiometer. Subjects were required to respond to $30 \mathrm{~dB}$ at 500,1000 , and $2000 \mathrm{~Hz}$ in at least one ear. All but three subjects passed the hearing screening test. These three subjects were subsequently determined to be capable of responding to speech in a sound field environment and were included in the experiment.

To insure that the subjects would be able to follow the verbal instructions of the experiment, each subject was required to listen to a short audiotaped paragraph recorded by a male speaker on a Sony Cassette-Corder, Model TCM-818, in a sound field environment. After listening to the paragraph, the subjects named three items discussed in the paragraph. All subjects were able to recall the names of three items in the recorded paragraph and were judged to be capable of responding to the experimental instructions. 
Experimental Task

The experimental task for this study was a confrontation naming task using stimuli from the Boston Naming Test (BNT) (Kaplan, Goodglass, \& Weintraub, 1983). The BNT is a widerange vocabulary test with $60 \mathrm{black}$ and white line drawings, ordered from easiest (e.g. bed) to difficult (e.g. protractor). For the purpose of this study, the 60 items were divided into three lists of 20 items each. The lists were equated for difficulty on the basis of results from a recent study by Nicholas, Brookshire, MacLennan, Schumacher, and Porrazzo (1989). The order of the items within each list was randomly assigned. Specific BNT stimuli contained in each list are found in Appendix B. The individual stimuli were photographed and $2 " \times 2 "$ slides were made from the photographs to simplify ease of presentation.

Experimental conditions

Subjects were asked to name the stimuli of each of the three 20 item lists following each of three types of instructions: encouraging, discouraging, and neutral. The instructions were recorded by an experienced male speechLanguage Pathologist on an audiotape (Sony Cassette-Corder) and were presented by an audio deck (Dual C-939, stereo Cassette Deck-Dolby system) and Sony active speaker system (Model\# SA-55) in a sound field environment. 
The instructions were worded as follows:

1. Encouraging: "This will be a simple naming task for you to complete. You will have 30 seconds to respond to a picture before the next one is shown. The experimenter will not be able to answer any questions during the test. However, she will discuss your performance afterwards if you wish. I want you to name some pictures that are easily identified by individuals with speech and language problems such as yourself. Past research has shown that these pictures are correctly identified in a testing situation such as the one you are in now. The test will begin when the first picture is shown."

2. Discouraging: "This will be a difficult naming task for you to complete. You will have 30 seconds to respond to a picture before the next one is shown. The experimenter will not be able to answer any questions during the test. However, she will discuss your performance afterwards if you wish. I want you to name some pictures that are hard to identify by individuals with speech and language problems such as yourself. Past research has shown that these pictures are incorrectly identified in a testing situation such as the one you are in now. The test will begin when the first picture is shown.

3. Neutral: "The experimenter will be showing you some pictures and I want you to name each one. You will have 30 seconds to respond to a picture before the next one is shown. The experimenter will not be able to answer any questions during the test.

However, she will discuss your performance afterwards if you wish. The test will begin when the first picture is shown.

The order of presentation of instructional conditions (encouraging, discouraging, and neutral) was counterbalanced across the subjects. Assignment of the lists to conditions was also counterbalanced within the instructional conditions. Specific information on the counterbalancing procedure is presented in Appendix C. 
PROCEDURES

\section{Experimental Task}

After the subject had passed the vision and hearing screenings and given evidence that he/she could understand the task instructions, the naming tasks were presented in the order described in Appendix $c$. The subjects were tested individually in a clinic room in the speech Pathology clinic of the PVAMC. Instructions for each naming task were presented with the audio deck and Sony active speaker system. The naming task stimuli were presented using the Kodak Ektagraphic slide projector. An illustration of positioning during the experiment is provided in Figure 1.

The subjects were asked to name each stimulus verbally. They were given 30 seconds to respond after the presentation of the stimulus on the viewing screen. No prompts or cues were provided to assist the subject in the naming of the items. When a subject inquired about the correctness of a response, the experimenter responded with "We can't talk about it now, but we will discuss it later."

Twenty to thirty minute breaks were provided between instructional conditions. At the end of the experiment, each subject was asked if he/she felt he/she did better on one list than another. The experimenter also asked if they were aware of the type of instruction given and if this affected their performance. 


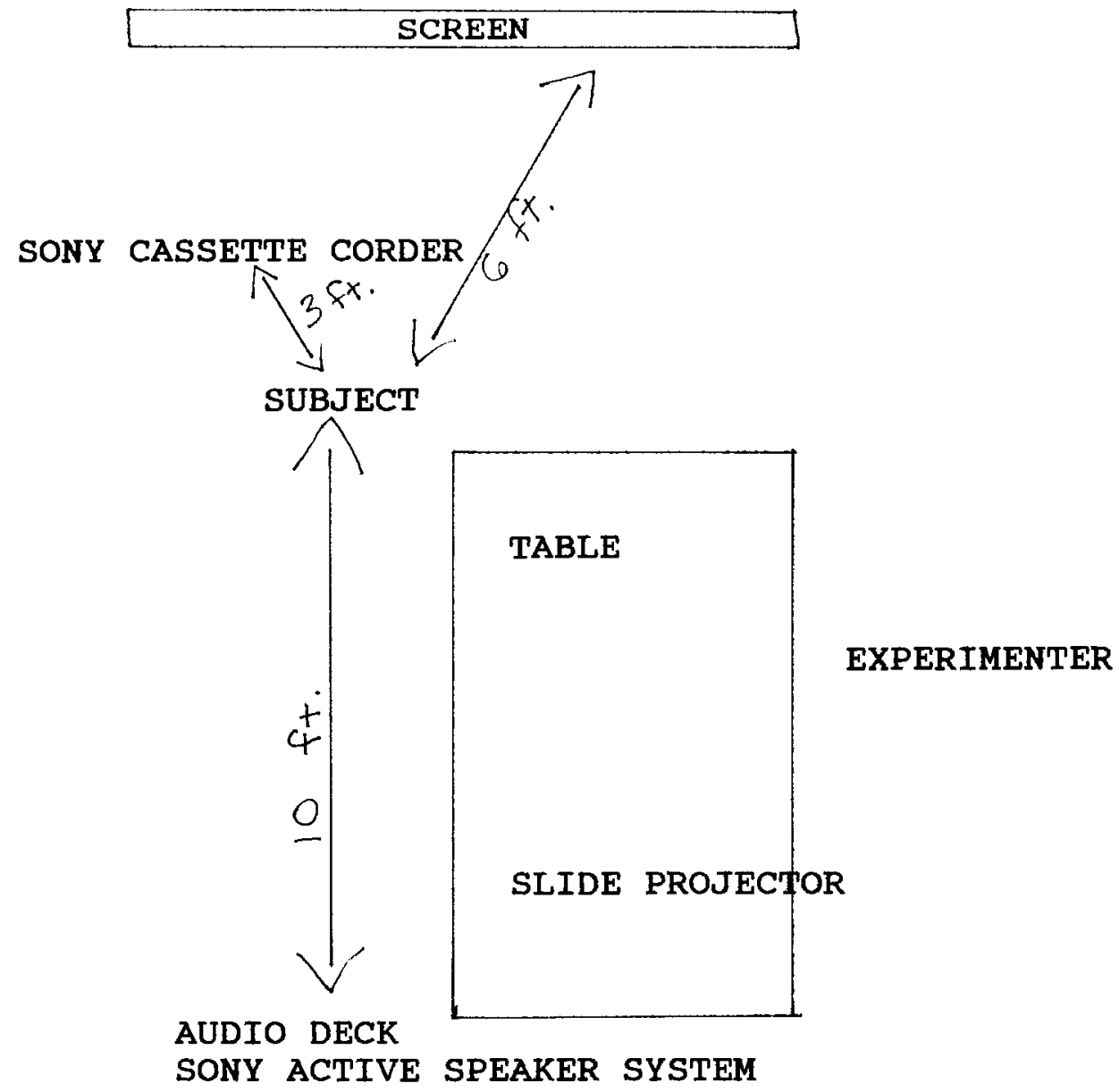

Figure 1. Experimental set Up. Top View. 
Scoring

Naming responses were scored using a 9 point scale adapted from the system used by Nicholas, Brookshire, Maclennan, Schumaker, and Porrazzo (1989). The scoring system is presented in Table I. For this study, the following revisions were employed:

1. A score of 5, Associated Response, did not include the subjects' personal reaction to the item, an incorrect response, or an indication that the subject did not know the name as in the study by Nicholas et al. In this study, personal reactions and/or giving an incorrect response (e.g. dice for dominoes) were scored as 1, Incorrect Response.

2. A score of 0 , No Response, was added to the scoring system. The response of "I don't know" was scored as 0 . A score of 0 was also given when the subject did not verbally respond to the stimulus picture.

3. Subjects were not penalized for minor production errors. These included instances when the subject's response differed by one phoneme in either addition, substitution, or omission (e.g. wamel for camel). A score of 2, Mispronunciation, was given for responses that differed by more than one phoneme (e.g. ohorn for acorn).

4. In cases where the subject was clearly able to retrieve the word but had to make multiple attempts to phonologically achieve the target (e.g. pel-penpel-pelican), only the final response was scored.

Scoring Reliability for Naming Task Responses

The subjects' naming responses were scored on-line by the experimenter. Responses were also audiotaped to provide a subsequent measure of scoring reliability. To accomplish this, ten 20-item lists ( 200 responses) were randomly selected 


\section{TABLE I}

\section{SCORING SYSTEM}

The scoring system consists of nine possible types of responses:

scoring system

8 Correct Name

7 other Name

6 Multiple Attempts

5 Associated Response

4 Visual Misperception

3 Wrong part

2 Mispronunciation

1 Incorrect response

0 No response
Example of response

House (for house)

Building (for house)

House, Building (for house)

People live in it (for house)

umbrella (for mushroom)

door (for house)

crushroom (for mushroom)

dice (for dominoes)

"I don't know" or no response

(adapted from Nicholas, Brookshire, MacLennan, Schumaker, \& Porrazzo, 1989) 
to measure intra-rater and inter-rater reliability. The latter was obtained by having a Speech-Language Pathology graduate student, trained in the use of the scoring system described in Table I, score the 200 responses. By comparing these scores with those of the experimenter, point-to-point agreement was calculated to be $87 \%$. Intra-rater reliability was determined by having the examiner score the same 200 responses from the tape recorder two weeks after conclusion of the experiment. The percentage of intra-rater reliability for the examiner was $92 \%$. 
CHAPTER IV

\section{RESULTS AND DISCUSSION}

\section{RESULTS}

\section{Data Analysis}

Mean scores for the naming task for each instructional condition were calculated for each subject. These are shown in Appendix D. For each instructional condition, the subjects' mean scores were pooled and averaged to derive a grand mean. These data were submitted to a repeated measures analysis of variance (ANOVA) (Winer, 1971) to determine the influence of instructions (encouraging, discouraging, and neutral) and lists (A, B, and $C$ ) at the .01 significance level.

Instructions. Figure 2 shows the group means for the three instruction conditions. These data show that there are no differences among the group means for the different instructions. None of the differences were significant $(\mathrm{F}=.621, \mathrm{df}=2,34, \mathrm{P}=.543)$. When the subjects' responses to the question about on which instructional set they did best on were tabulated, seven out of the eighteen subjects identified the encouraging instructional condition. For a detailed description of the subjects' responses, see Appendix E. Not one of the subjects stated that he/she was aware of the type 


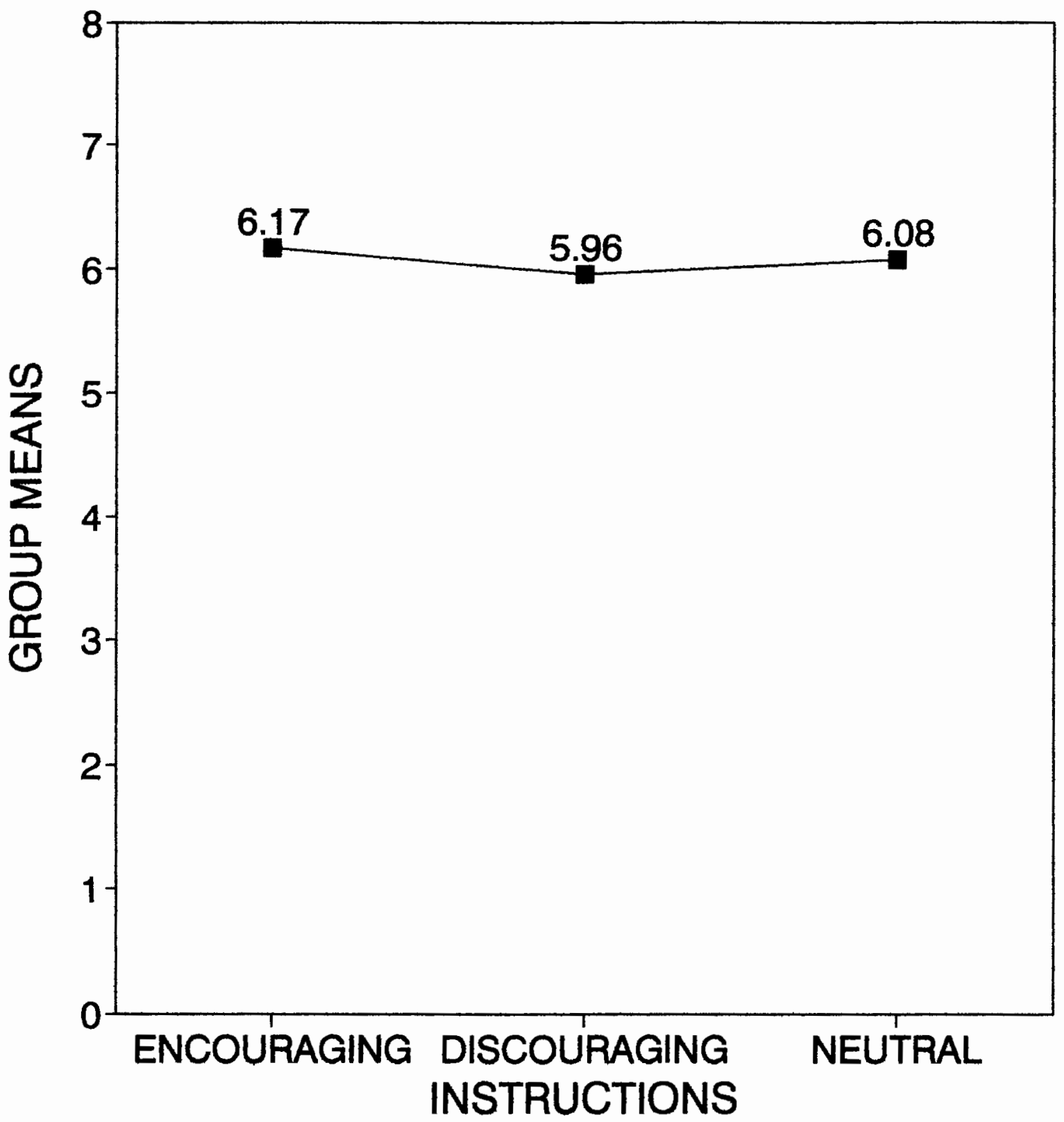

Figure 2. Group Means for Instructions. 
of instruction given and how this may have affected his/her performance.

Lists. Figure 3 shows group means for the three 20 item naming tasks irrespective of instructional sets. ANOVA results yielded no significant differences among the lists $(\mathrm{F}=1.28, \mathrm{df}=2,34, \mathrm{P}=.29)$.

These results support the null hypothesis that instructions will not significantly affect the naming performance of aphasic subjects.

\section{DISCUSSION}

The results of the present study do not support stoicheff's (1960) findings that motivating instructions influence aphasic subjects' performance on a naming task. In this study, when the effects of encouraging, discouraging, and neutral instructions on aphasic subjects' naming performance were compared, instructions did not affect naming performance. Although the two studies are different, there are several reasons why the findings of this study are unlike the findings of stoicheff. Most of these explanations relate to the methodology of the two investigations and will be discussed in detail.

\section{Group Design}

In Stoicheff's (1960) group design, the subjects were randomly assigned to one of the three groups. Each group was 


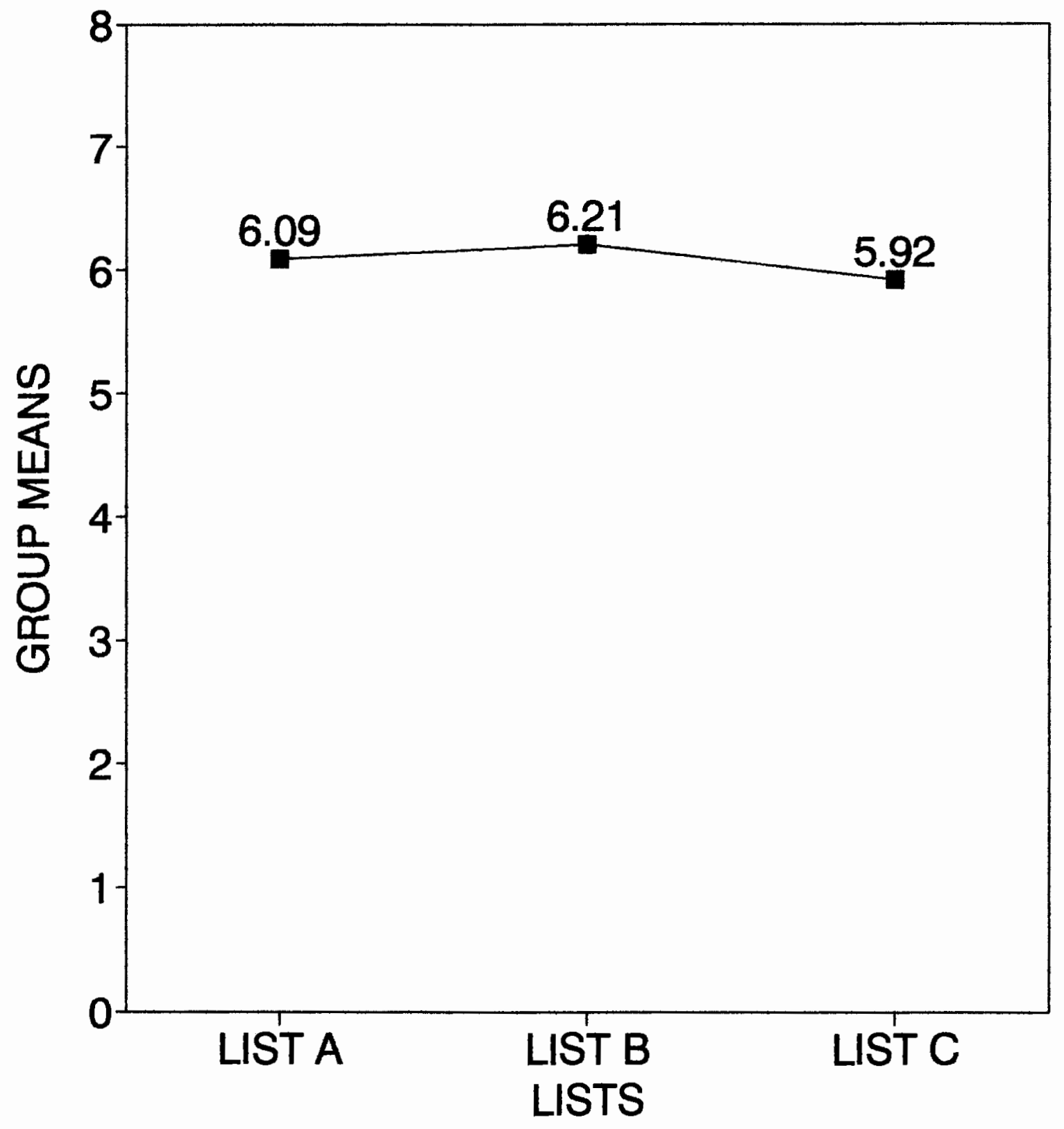

Figure 3. Group Means for Naming Task. 
assigned to one of the three instructional conditions (encouraging, discouraging, and neutral). In the present study, the group of subjects were assigned to all three conditions. This format was chosen to compare each subject's score under each instructional condition to determine if differences actually occurred.

\section{Experimental Conditions}

In both stoicheff's (1960) investigation and the present investigation, three instructional conditions were used (encouraging, discouraging, and neutral). stoicheff's subjects received the experimental instructions in a preliminary test designed for subject selection, in two preliminary testing session, and in a final testing session. During the first two testing sessions, the subjects were conditioned to perceive the experimenter as an encouraging, discouraging, or neutral figure corresponding to their assigned instructional condition. Comparisons among the groups were made on the basis of their performance on the last testing session only.

In this study, the subjects received the experimental instructions for each condition once. They were not conditioned to perceive the experimenter as an encouraging, discouraging, or neutral figure but only to attend to the instructions. Therefore, the effects of the instructional 
conditions were isolated without the contamination of the experimenter's attitudes.

\section{Content of Instructions}

The wording of Stoicheff's instructions was changed for the present study. Stoicheff's (1960) instructions were strongly encouraging and discouraging compared to the present instructions. Her instructions included feedback on past performances, the experimenter's attitude to the subjects' past performance, and expected success or failure on the following task. stoicheff's discouraging instructions were demeaning and comparable to a psychological build up of expected failure (e.g. "As I expected, you did even more poorly last time than the time before... I am disappointed with how much you have slipped behind..." [p. 79]). Similar instructions were not used in the present study because it was assumed that such instructions allowed in 1960 would not be approved by a Human Subjects Review Committee in 1991 due to the possible negative effects on a subject. Therefore, stoicheff's instructions may have been strong enough to elicit an emotional reaction from the subjects. One reason for the insignificant findings in the present study may be that the instructions were not strong enough to elicit either a positive or negative reaction from the subjects. In the present study, the subjects stated that they did not notice a 
difference between the instructions given at the beginning of each task. It is possible that they may have ignored the instructions because it was obvious to them what the task involved or they may not have felt the task was important enough to elicit a strong response.

\section{Feedback}

In addition to the demanding instructional conditions, Stoicheff's (1960) subjects received favorable and unfavorable feedback prior to and during the encouraging and discouraging instructional conditions, respectively, such as "You are doing fine" and "You missed that one." The negative feedback may have been a punishment to the subjects. Comparable comments were not given in the present study in order to isolate the instructional conditions. In stoicheff's study, it is difficult to determine if the instructions, the comments, or both affected the subjects' performance. In the present study, the effects of the instructional conditions alone did not significantly influence language performance of aphasic subjects. Therefore, it is possible that stoicheff's finding that motivating instructions significantly affect language performance may be deceiving because of the influence of the additional variables of comparable comments and the conditioning process to perceive the experimenter as an encouraging, discouraging, or neutral character. 
other Methodological Differences

Presentation of Instructions. The instructions in the present study were audiotaped to isolate the instructions and insure reliability during the experiment. The experimenter in stoicheff's (1960) study verbally presented the instructions for each testing session. Her results depended strongly on how convincing the experimenter was in the experiment. consequently, the experimenter's voice and nonverbal communication may have affected the results of her investigation. Stoicheff's experimenter may have presented negative or positive nonverbal behaviors irrespective of the instructional condition being presented. This was additional evidence that stoicheff did not isolate the effects of instructional condition. In the present study, the experimental instructions were more impersonal and artificial than in stoicheff's study; but, the instructional conditions were exactly the same for each subject and excluded influential nonverbal communication signals.

scoring. A different scoring system was used in each study. In stoicheff's study, the subjects' responses were scored as either correct or incorrect. In the present study, the subjects' responses were scored on a scale from 0 to 8 . The present scoring system was chosen because current standardized testing instruments for aphasia use a scaled scoring system. This type of scoring system allows for an 
objective score taking into account not only the accuracy of a response but also the subject's behavior as he attempts to respond. The scoring system used in this study could have been a contributing factor to the differences found between the two studies. If the scoring system used by Stoicheff (1960) was employed in the present study, many subjects would have received an incorrect score for responses that were clearly associated with the target response.

Individual Variability. Excluding the changes in methodology, an important uncontrollable variable in both studies was the personality of subjects. Some people may like to be challenged and may work harder under the threat of failure while others become anxious. Under encouraging instructions, a person's anxiety level may decrease, thus, improving their performance. However, this was not evident in the present study. 


\section{CHAPTER V}

\section{SUMMARY AND IMPLICATIONS}

\section{SUMMARY}

The purpose of this investigation was to examine the influence of three instructional conditions (encouraging, discouraging, and neutral) on eighteen aphasic adults' performance on a naming task. Each subject listened to each audiotaped instructional condition followed by a 20 picture naming task presented with a slide projector for a total of three tasks and 60 pictures. Subjects' mean scores were combined and averaged to derive a grand mean score for each instructional condition. A repeated measures analysis of variance was applied to determine if the differences were significant at the .01 level. No significant differences were found.

The present investigation did not confirm the long accepted findings of stoicheff (1960) that motivating instructions influence language performance of aphasic subjects. The validity of stoicheff's study was questioned because other variables, besides the instructional conditions, were involved that may have contributed to her results. This study isolated the instructions to determine if instructions were, in fact, a variable that affects language 
performance. However, this was not found to be the case.

\section{IMPLICATIONS}

\section{Clinical Implications}

The results of the present investigation suggest that aphasia clinicians need not be fearful in using encouraging, discouraging, and neutral instructions. It may be important for the clinician to tell the truth to the individual with aphasia regarding the difficulty of an assessment measure or various tasks in a treatment session. This may prepare the individual to work harder and expect some failure. Using encouraging instructions may be important to use with an individual who lacks confidence in his abilities. Encouraging instructions, hopefully, may decrease any anxiety the individual may have and facilitate optimum performance. Some individuals may need to be challenged to improve performance and others may need encouragement.

\section{Further Research Implications}

The present study objectively assessed the effects of three instructional conditions on aphasic adults' naming task performance. Significant differences were not found. Research of the effects of instructional conditions should not cease. Instructions were isolated in this experiment and that is not the case in real life. Further research could focus on a similar study but involving the experimenter during the 
testing session by presenting the instructions with appropriate nonverbal cues and/or by giving favorable or unfavorable comments, such as in stoicheff's (1960) study. In addition, the experimenter could be a familiar clinician to the subjects which may create a more realistic setting.

Throughout the data collection phase of the experiment, it was the feeling of the primary experimenter that the subjects did not notice or respond to the different instructions. As mentioned earlier, it is possible that the instructions did not evoke either a positive or negative reaction as they did in stoicheff's (1960) study. Further research could involve changing the instructions in a way that may evoke a response by emphasizing the discouraging or encouraging intent of the instructions. But, as in the present study, the instructions must be approved by a Human Subjects Review Committee. A similar study could focus on having the subjects identify instructions as encouraging, discouraging, or neutral. It is possible that the subjects in the present study could not understand the abstraction of the instructions.

A study could be conducted in which aphasic subjects are given a task known to be difficult and provide a period of motivational training beforehand to determine if such training would improve language performance. Further research could focus on the pre-aphasia and post-aphasia personalities of the 
subjects; e.g. passive or assertive. An experimenter could interview either the significant others or family members of the subjects to determine personality types. A future investigation could compare personality types to performance under the three instructional sets used in the present study. An assertive individual may be challenged by discouraging instructions and work harder to succeed while the anxiety level of a passive individual may increase under these conditions causing failure. It is worthwhile to know whether instructions are a variable that affects the language performance of aphasic adults and further research is encouraged to confirm or reject the findings of the present study. 


\section{REFERENCES}

Altschuler, S.L. (1974). The effects of supplemental oxygen respiration on hemiplegic aphasic adults. In $B$. Porch (Ed.), Clinical Aphasiology: Proceedings of the Conference, 1974. Minneapolis: BRK Publishers.

Basili, A.G., Diggs, C.C., \& Rao, P.R. (1980). Auditory processing of brain damaged adults under competitive listening conditions. Brain and Language, 9, 362-371.

Bergman, P.S. \& Green, M. (1951). Aphasia effects of intravenous sodium amytal. Neurology, 1, 471-475.

Billow, B.W. (1949). Observation of the use of sodium amytal in the treatment of aphasia. Medical Record, 162, 12-13.

Biorn-Hansen, V. (1957). Social and emotional aspects of aphasia. Journal of Speech and Hearing, 22 (1), 53-59.

Broida, H. (1979). Communication breakdown of brain injured adults. Houston: College Hill Press.

Brookshire, R.H. (1971). Effects of trial time and inter-trial interval on naming by aphasic subjects. Journal of Communication Disorders, $\underline{3}, 289-301$.

Brookshire, R.H. (1972). Effects of task difficulty on naming performance of aphasic subjects. Journal of speech and Hearing Research, 15, 551-558.

Brookshire, R.H. (1976). Effects of task difficulty on sentence comprehension performance of aphasic subjects. Journal of Communication Disorders, 9, 167-173.

Brookshire, R.H. (1986). An introduction to aphasia (3rd ed.). Minneapolis: BRK Publishers.

Brookshire, R., Nicholas, L., Redmond, N.K., \& Krueger, K. (1979). Effects of clinician behaviors on acceptability of patients' responses in aphasia treatment sessions. Journal of Communication Disorders, 12, 369-384 .

Brumfitt, S. \& Clarke, P. (1983). An application of psychotherapeutic techniques to the management of aphasia. In C. Code \& D.J. Muller (Eds.), Aphasia Therapy. London: Edward Arnold. 
Buck, M. (1968). Dysphasia: Professional guidance for family and patient. Englewood Cliffs: Prentice-Hall.

Chester, S.L. \& Egolf, D.B. (1974). Nonverbal communication and aphasia therapy. Rehabilitation Literature, 35 (8), 231-233.

Corcoran, C.M. \& McAleer, C.A. (1980). Effects of client aphasia on client evaluation and counselor behavior. Journal of Counseling Psychology, 27 (2), 166-170.

Darley, F.L., Keith, R.L., \& Sasanuma, S. (1977). The effects of alerting and tranquilizing drugs upon the performance of aphasic patients. In R.H. Brookshire (Ed.), clinical Aphasiology: Proceedings of the Conference, 1977. Minneapolis: BRK Publishers.

DeRenzi, E., Faglioni, P., \& Previdi. (1978). Increased susceptibility of aphasics to a distractor task in the recall of verbal commands. Brain and Language, $6,14-21$.

Dorland's medical dictionary. (1965). Philadelphia: w.B. Saunders.

Dreher, B.B., Ege, D.D., \& Harrold, R. (1980). A proposed motivation checklist for communicatively impaired adults. Aphasia, Apraxia, Agnosia, 1 (3), 50-53.

Dubner, H. (1972). The role of the speech pathologist in the early treatment of the aphasic patient. Rehabilitation Literature, 33 (11), 330-331, 388 .

Duffy, J.R., Boyle, M., \& Plattner, L. (1980). Listener reactions to personal characteristics of fluent and nonfluent aphasic speakers. In R.H. Brookshire (Ed.), Clinical Aphasiology: Proceedings of the Conference, 1980. Minneapolis: BRK Publishers.

Eisenson, J. (1963). Aphasic language modifications as a disruption of cultural verbal habits. ASHA, $\underline{5}$ (2), 503506 .

Eisenson, J. (1984). Adult aphasia (2nd ed.). Englewood Cliff: Prentice-Hall.

Florence, C.L. \& Conway, W.F. (1986). The center for independent living: A case study. In R.C. Marshall (Ed.), Case studies in aphasia rehabilitation: For clinicians by clinicians (pp.151-166). Austin, TX: Pro-Ed. 
Irwin, J.A. (1981). A view from within: Experience with aphasia. In R.H. Brookshire (Ed.), Clinical Aphasiology (pp. 201-204). Minneapolis: BRK Publishers.

Kaplan, Goodglass, \& Weintraub. (1983). The Boston Naming Test. Philadelphia: Lea \& Febiger.

Linn, L. (1947). Sodium amytal in treatment of aphasia. Archives of Neurological Psychiatry, 58, 357-358.

Lubinski, R. (1986). A social communication approach to treatment of aphasia in an institutional setting. In R.C.Marshall (Ed.), Case studies in aphasia rehabilitation: For clinicians by clinicians (pp.167182). Austin, TX: Pro-Ed.

Malone, R.L. (1969). Expressed attitudes of families of aphasics. Journal of Speech and Hearing Disorders, 34, 146-150.

Marshall, R.C. (1987). Reapportioning time for aphasia rehabilitation: A point of view. Aphasiology, 1 , 59-73.

Marshall, R.C. \& King, P.S. (1973). Effects of fatigue produced by isokinetic exercise on the communication ability of aphasic adults. Journal of Speech and Hearing Research, 16 (2), 220-230.

Marshall, R.C., Tompkins, C.A., \& Phillips, D.S. (1980). Effects of scheduling on the communicative assessment of aphasic patients. Journal of Communication Disorders, 13, 105-114.

Marshall, R.C. \& Watts, M.T. (1976). Relaxation training: Effects on the communicative ability of aphasic adults. Archives of Physical Medicine and Rehabilitation, 57, 464-467.

McNeil, M.R. \& Prescott, T.E. (1978). Token test. Baltimore: University Park Press.

Nicholas, L.E., Brookshire, R.H., MacLennan, D.L., Schumacher, J.G., \& Porrazzo, S.A. (1989). Revised administration and scoring procedures for the Boston Naming Test and norms for non-brain damaged adults. Aphasiology, 33 (6), 569580 . 
Porch, B. (1967). Porch index of communicative abilities. Palo Alto, CA: Consulting Psychologists.

Porter, J.L. \& Dabul, B. (1977). The application of transactional analysis to therapy with wives of adult aphasic patients. ASHA, 19, 244-248.

Ricco-Schwartz, S. (1982). Fostering an empathic approach: An in-service curriculum for nonmedical professionals, paraprofessionals, and families of aphasic clients. Gerontology \& Geriatrics Education, 2 (3), 199-206.

Sarno, M.T., Sarno, J.E., \& Diller, L. (1972). The effects of hyperbaric oxygen on communication function in adults with aphasia. Journal of Speech and Hearing Research, 15, $42-48$.

Scheull, H., Jenkins, J.J., \& Iminez-Pabon, E. (1964) . Aphasia in adults: Diagnosis, prognosis, and treatment. New York: Harper and Row.

Shill, M. (1979). Motivational factors in aphasia therapy: Research suggestions. Journal of Communication Disorders, 12, 503-517.

Skelly, M. (1975). Aphasic patients talk back. American Journal of Nursing, 75 (7), 1140-1142.

Stoicheff, M.I. (1960). Motivating instructions and language performance of dysphasic subjects. Journal of Speech and Hearing Research, $\underline{3}$ (1), 75-85.

Tompkins, C.A., Marshall, R.C., \& Phillips, D.S. (1980). Aphasic patients in a rehabilitation program: Scheduling speech and language services. Archives of Physical Medicine and Rehabilitation, 61, 252-254.

Vogel, D. (1986). The patient after the fall. In R.C. Marshall (Ed.), Case studies in aphasia rehabilitation: For clinicians by clinicians (pp.1930). Austin, TX: Pro-Ed.

Wender, D. (1989). Aphasia victim as investigator. Archives of Neurology, 46, 91-94.

Wender, D. (1990) . Quality: A personal perspective. ASHA, 32, 41-44. 
Wepman, J.M. (1953). A conceptual model for the processes involved in recovery from aphasia. Journal of Speech and Hearing Disorders, 18, 4-13.

West, R. \& Stockel, S. (1965). The effect of meprobamate on recovery from aphasia. Journal of Speech and Hearing Research, 8 , 57-62.

Winer, B.E. (1971). Statistical principles in experimental design. New York: McGraw Hill. 


\section{APPENDIX A}

DESCRIPTION OF APHASIC SUBJECTS

\begin{tabular}{|c|c|c|c|c|}
\hline Subject & Age & $\begin{array}{l}\text { Months } \\
\text { Post Onset }\end{array}$ & $\begin{array}{l}\text { Overall PICA } \\
\text { Percentile } \\
\text { and Test Date }\end{array}$ & Etiology \\
\hline$\overline{01(R)}$ & 61 & 47 & $70,11 / 88$ & CVA \\
\hline 02 (L) & 55 & 27 & $87-88, \quad 3 / 89$ & Trauma \\
\hline $03(\mathrm{R})$ & 61 & 34 & $81,7 / 88$ & CVA \\
\hline 04 (L) & 61 & 49 & $72,6 / 88$ & CVA \\
\hline 05 (R) & 54 & 34 & $60,6 / 90$ & Anerysym \\
\hline $06(R)$ & 49 & 49 & $78,3 / 89$ & CVA \\
\hline $07(\mathrm{R})$ & 68 & 61 & $72,3 / 88$ & CVA \\
\hline 08 (L) & 57 & 39 & $77,3 / 89$ & CVA \\
\hline 09 (R) & 58 & 53 & $61,9 / 87$ & CVA \\
\hline $10(\mathrm{R})$ & 61 & 32 & $65,4 / 90$ & CVA \\
\hline $11 *(\mathrm{R})$ & 68 & 132 & $87,10 / 86$ & CVA \\
\hline $12(\mathrm{R})$ & 63 & 18 & $81,12 / 89$ & CVA \\
\hline $13(\mathrm{R})$ & 30 & 144 & $85,11 / 88$ & Tumor \\
\hline $14(\mathrm{R})$ & 56 & 18 & $44,2 / 91$ & CVA \\
\hline $15(\mathrm{R})$ & 37 & 132 & $66,10 / 86$ & Trauma \\
\hline $16(\mathrm{R})$ & 49 & 4 & $84,1 / 91$ & CVA \\
\hline 17 (R) & 57 & 47 & $81-82, \quad 3 / 89$ & CVA \\
\hline $18 *(R)$ & 61 & 238 & $79,9 / 83$ & CVA \\
\hline
\end{tabular}

Key: "*" indicates female subjects

Premorbid handedness is denoted in () 
APPENDIX B

STIMULUS LISTS

LIST A

helicopter dominoes pyramid broom wreath harp muzzle compass mushroom racquet house noose snail toothbrush scissors protractor yoke bench knocker octopus
LIST B

pencil

asparagus

accordion

bed

stethoscope

pelican

unicorn

whistle

flower

beaver

seahorse

camel

hammock

igloo

acorn

tripod

wheelchair

sphinx

latch

mask
IIST C

abacus

saw

stilts

globe

harmonica

pretzel

dart

trellis

comb

scroll

funnel

canoe

palette

cactus

rhinoceros

tree

volcano

tongs

hanger

escalator 
APPENDIX $C$

ORDER OF PRESENTATION OF INSTRUCTIONS

\begin{tabular}{|c|c|c|c|c|}
\hline $\begin{array}{l}\text { Subject } \\
\text { Subject } \\
\text { Subject }\end{array}$ & $\begin{array}{l}\# 1: \\
\# 2: \\
\# 3:\end{array}$ & $\begin{array}{l}1 \text { - list a } \\
1 \text { - list b } \\
1 \text { - list } c\end{array}$ & $\begin{array}{l}2 \text { - list } b \\
2 \text { - list } \\
2 \text { - list a }\end{array}$ & $\begin{array}{l}3 \text { - list } \\
3 \text { - list a } \\
3 \text { - list b }\end{array}$ \\
\hline $\begin{array}{l}\text { Subject } \\
\text { Subject } \\
\text { Subject }\end{array}$ & $\begin{array}{l}\# 4: \\
\# 5: \\
\# 6:\end{array}$ & $\begin{array}{l}2 \text { - list a } \\
2 \text { - list b } \\
2 \text { - list } c\end{array}$ & $\begin{array}{l}3 \text { - list b } \\
3 \text { - list } \\
3 \text { - list a }\end{array}$ & $\begin{array}{l}1 \text { - list } \\
1 \text { - list a } \\
1 \text { - list b }\end{array}$ \\
\hline $\begin{array}{l}\text { Subject } \\
\text { Subject } \\
\text { Subject }\end{array}$ & $\begin{array}{l}\# 7: \\
\# 8: \\
\# 9:\end{array}$ & $\begin{array}{l}3 \text { - list a } \\
3 \text { - list b } \\
3 \text { - list } c\end{array}$ & $\begin{array}{l}1 \text { - list } b \\
1-\text { list } \\
1 \text { - list a }\end{array}$ & $\begin{array}{l}2 \text { - list } \\
2 \text { - list } \\
2 \text { - list b }\end{array}$ \\
\hline $\begin{array}{l}\text { Subject } \\
\text { Subject } \\
\text { Subject }\end{array}$ & $\begin{array}{l}\# 10: \\
\# 11: \\
\# 12:\end{array}$ & $\begin{array}{l}1 \text { - list } c \\
1 \text { - list a } \\
1 \text { - list b }\end{array}$ & $\begin{array}{l}3 \text { - list a } \\
3 \text { - list b } \\
3 \text { - list } c\end{array}$ & $\begin{array}{l}2 \text { - list b } \\
2 \text { - list } \\
2 \text { - list a }\end{array}$ \\
\hline $\begin{array}{l}\text { Subject } \\
\text { Subject } \\
\text { Subject }\end{array}$ & $\begin{array}{l}\# 13: \\
\# 14: \\
\# 15:\end{array}$ & $\begin{array}{l}2 \text { - list } c \\
2 \text { - list a } \\
2 \text { - list b }\end{array}$ & $\begin{array}{l}1 \text { - list a } \\
1 \text { - list b } \\
1 \text { - list } c\end{array}$ & $\begin{array}{l}3 \text { - list b } \\
3 \text { - list } \\
3 \text { - list a }\end{array}$ \\
\hline $\begin{array}{l}\text { Subject } \\
\text { Subject } \\
\text { Subject }\end{array}$ & $\begin{array}{l}\text { \#16: } \\
\# 17: \\
\# 18:\end{array}$ & $\begin{array}{l}3 \text { - list } \\
3 \text { - list } a \\
3 \text { - list b }\end{array}$ & $\begin{array}{l}2-\text { list } a \\
2-\text { list } b \\
2-\text { list } c\end{array}$ & $\begin{array}{l}1-1 \text { list } b \\
1-\text { list } \\
1-\text { list } a\end{array}$ \\
\hline
\end{tabular}

Order of Instructions:

$$
\begin{aligned}
& 1 \text { - Encouraging } \\
& 2 \text { - Discouraging } \\
& 3 \text { - Neutral }
\end{aligned}
$$




\section{MEAN SCORES FOR APHASIC SUBJECTS} UNDER EACH INSTRUCTIONAL CONDITION

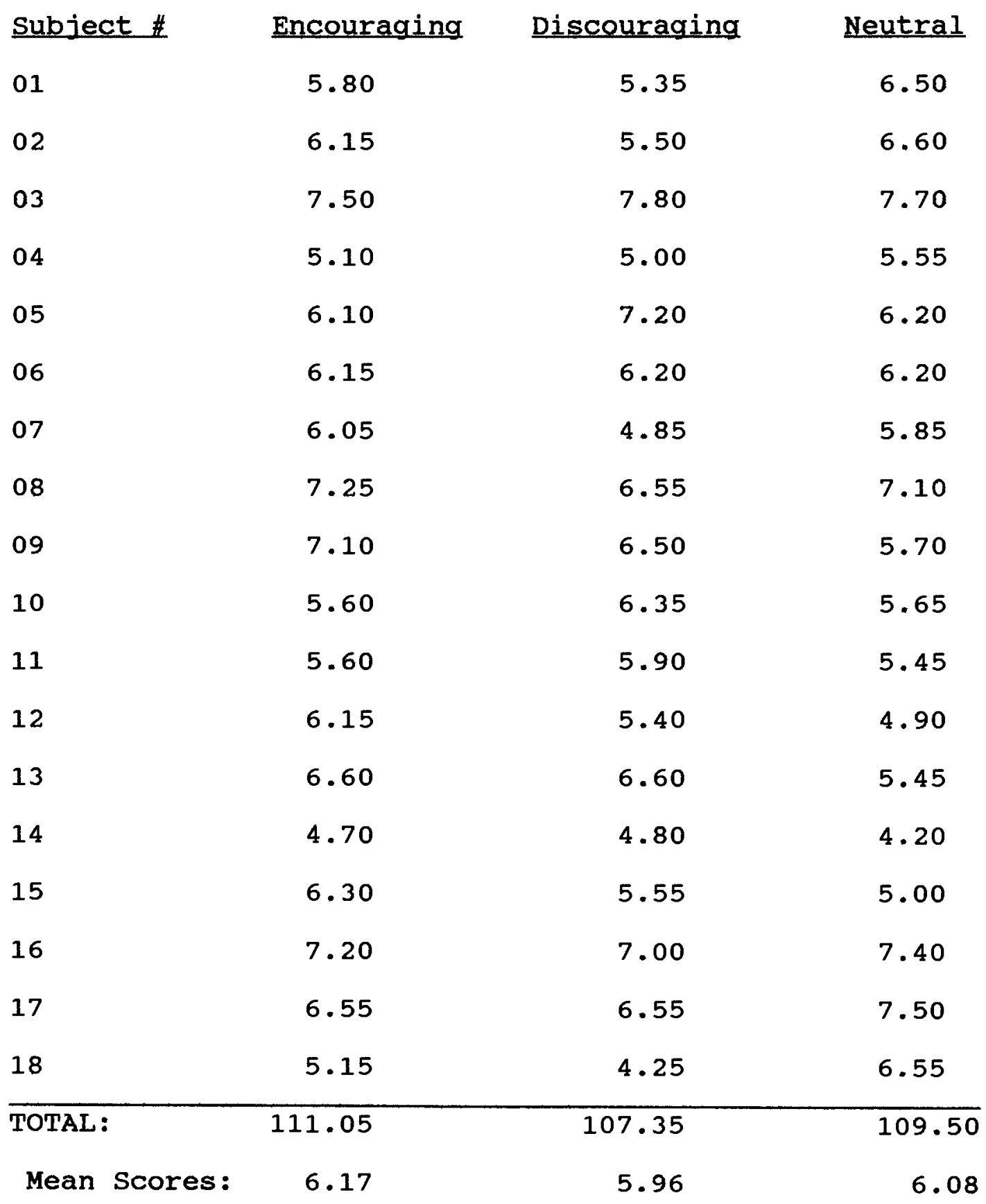




\section{APPENDIX E \\ SUBJECTS' RESPONSES TO \\ EXPERIMENTER'S QUESTION}

SUBJECT

INSTRUCTIONAL CONDITION PRECEEDING THE TASK WHICH THE SUBJECT REPORTED BEST PERFORMANCE ON

01

discouraging

02

equally well on all three

03

encouraging

04

neutral

05

discouraging

06

equally well on all three

07

neutral

08

encouraging and neutral

09

encouraging

10

encouraging

11

encouraging

12

discouraging

13

encouraging

14

encouraging

15

encouraging

16

discouraging and neutral

equally well on all three

discouraging 